\title{
Cytoprotective and anti-inflammatory effects of PAL31 overexpression in glial cells
}

\author{
Fan-Wei Tseng ${ }^{1,2}$, Dann-Ying Liou ${ }^{2,3}$, May-Jywan Tsai ${ }^{2,3^{*}}$, Wen-Cheng Huang ${ }^{2,3,4^{*}+}$ and Henrich Cheng ${ }^{1,2,3,4^{*}+}$
}

\begin{abstract}
Background: Acute spinal cord injury (SCI) leads to a series of reactive changes and causes severe neurological deficits. A pronounced inflammation contributes to secondary pathology after SCl. Astroglia respond to SCl by proliferating, migrating, and altering phenotype. The impact of reactive gliosis on the pathogenesis of SCl is not fully understood. Our previous study has identified an inflammatory modulating protein, proliferation related acidic leucine-rich protein (PAL31) which is upregulated in the microglia/macrophage of injured cords. Because PAL31 participates in cell cycle progression and reactive astroglia often appears in the injured cord, we aim to examine whether PAL31 is involved in glial modulation after injury.

Results: Enhanced PAL31 expression was shown not only in microglia/macrophages but also in spinal astroglia after $\mathrm{SCl}$. Cell culture study reveal that overexpression of PAL31 in mixed glial cells or in C6 astroglia significantly reduced LPS/IFNy stimulation. Further, enhanced PAL31 expression in C6 astroglia protected cells from $\mathrm{H}_{2} \mathrm{O}_{2}$ toxicity; however, this did not affect its proliferative activity. The inhibiting effect of PAL31 on LPS/IFNy stimulation was observed in glia or C6 after co-culture with neuronal cells. The results demonstrated that the overexpressed PAL31 in glial cells protected neuronal damages through inhibiting NF-kB signaling and iNOS.

Conclusions: Our data suggest that PAL31upregulation might be beneficial after spinal cord injury. Reactive gliosis might become a good target for future therapeutic interventions.
\end{abstract}

Keywords: Spinal cord injury, Proliferation related acidic leucine-rich protein, Inflammation, $\mathrm{H}_{2} \mathrm{O}_{2}$ toxicity, Astroglia, C6 glioma, Microglia

\section{Background}

Spinal cord injury (SCI) causes severe and often permanent neurological deficits through direct trauma and delayed secondary damage [1,2]. The cascade of secondary injury is mediated by inflammatory response, involving macrophage and microglial activation [3-5]. Neurons in injured cord have become more sensitive to a secondary injury. Several lines of evidence have reported that attenuating inflammation decreases secondary damage and the functional deficit after SCI [6,7]. Astrocytes respond to SCI by proliferating, migrating, and altering phenotype. Reactive astrocytes can be found within the lesion, and they can also constitute a

\footnotetext{
*Correspondence: mjtsai2@vghtpe.gov.tw; wchuang@vghtpe.gov.tw; hc_cheng@vghtpe.gov.tw

${ }^{\dagger}$ Equal contributors

${ }^{2}$ Neural Regeneration Laboratory, Neurological Institute, Taipei Veterans General Hospital, No 322, Shih-Pai Road, Sec. 2, Taipei 112, Taiwan 'Department and Institute of Pharmacology, School of Medicine, National Yang-Ming University, Taipei, Taiwan

Full list of author information is available at the end of the article
}

physical barrier between the lesion and the surrounding tissue $[8,9]$. These cells are considered to be detrimental for axonal regeneration, but their function remains elusive.

After SCI, intracellular $\mathrm{Ca}^{2+}$ is transiently increased and initiates several damaging effects. One of these effects is activation of nitric oxide synthase (NOS) in mitochondria and cytoplasm. The activated NOS can generate peroxynitrite anion $\left(\mathrm{ONOO}^{-}\right)$, a reactive product of superoxide radical with nitric oxide. Peroxynitrite can trigger cellular damage by a variety of mechanisms [10,11]. Glial cells (astrocytes and microglia) synthesize NO after the transcriptional expression of inducible NOS which can be promoted by the endotoxin lipopolysaccharide (LPS) and/ or by certain cytokines, such as interferon- $\gamma$ (IFN $\gamma)[12,13]$.

Cyclic AMP has been shown to play critical role in neural regeneration [14] and this effect is mediated through the activation of protein kinase A (PKA). Previously, we had identified a phospho-motif in PKA substrates that correlated with SCI rat neural regeneration [15]. This 
novel molecule was identified as a proliferation related acidic leucine-rich protein (PAL31) with molecular weight of $31 \mathrm{kDa}$. PAL31 had been discovered in the developing nervous system and its expression level decreased following maturation. The functions of PAL31 has been discovered that participated in cell cycle progression [16], caspase-3 inhibition [17], and inflammatory modulation [15]. Interestingly, PAL31 was found to express in the infiltrated macrophages in the epicenter of the injured spinal cord and the amount of PAL31 reached its peak level over 6 days after transection of spinal cord [15]. This suggests that PAL31 may play a modulatory role on inflammation during SCI. On the other hand, PAL31 had been reported to co-localize with PCNA which participated in DNA replication and repair [16]. Proliferation of astroglia and microglia is increased at 1-7 days after SCI [18]. Astrocytes in spared gray and white matter of spinal cord undergo hypertrophy or gliosis after injury. Because PAL31 participates in cell cycle progression and reactive astroglia often appears in the injured cord, PAL31 could be expressed in spinal glia after SCI. In the present study, we aim to examine whether PAL31 is involved in glial modulation after spinal cord injury. To reveal the molecular mechanism of PAL31 in astroglia, a full-length PAL31 cDNA was first prepared. We conducted PAL31 overexpressing experiments in primary cultures derived from spinal cord tissues to mimic the interaction of glia and neurons in vivo. Here we present evidence showing that enhanced expression of PAL31 in astroglia might be beneficial after spinal cord injury.

\section{Methods}

\section{Materials}

Lipopolysaccharide (LPS; Escherichia coli O111:B4) and antibiotics were purchased from Sigma-Aldrich (St. Louis, USA). Rat interferon- $\gamma$ (IFN $\gamma$ ) was from Peprotech. A methylthiazol tetrazolium (MTT) kit was from Chemicon (USA). Culture multi-wells and pipettes were obtained from Orange Scientific (Graignette, Belgium). Cultured media and fetal bovine serum (FBS) were purchased from Gibco (Invitrogen Corporation, USA). Other reagents were purchased from Sigma-Aldrich unless stated otherwise.

\section{Spinal cord injury}

Adult female Spraque-Dawley (SD) rats $(250 \pm 20$ g) were used for inducing spinal cord injury (SCI) and the operation procedures have been described elsewhere [19-22]. Briefly, adult female SD rats were anesthetized with isoflurane and a laminectomy was performed. Vertebrate thoracic T7-T10 was exposed. Rats underwent a complete 'transection' operation at thoracic T8. Following injury, the incision was closed and sutured. Each rat was then returned to its cage. To avoid urinary tract infections, manual emptying of the urinary bladder was carried out twice daily. All surgical interventions and animal care were performed in accordance with the Laboratory Animal Welfare Act, the Guide for the Care and Use of Laboratory Animals, National Institutes of Health and were approved by the Animal Committee of Taipei Veterans General Hospital, Taiwan.

\section{Cell culture}

Mixed neuronal/glial cultures were prepared from embryonic SD rat spinal cords at gestation days 14-16 as described previously [23-25]. Briefly, cells were dissociated with mixtures of papain/protease/deoxyribonuclease I (0.1:0.1: $0.03 \%)$ and plated in poly-lysine coated multiwell plates $(12 \times 24 \mathrm{~mm})$ or on mixed glial cultures (for co-culture study, see below). Mixed glial cultures were prepared from adult SD rat spinal cords following methods described previously $[26,27]$ with modifications. Briefly, spinal cords, free of meninges, were dissociated by trypsinization. The dissociated cells were passed through nylon cloths (70 um), plated in $75 \mathrm{~cm}^{2}$ flasks and maintained in DMEM supplemented with 10\% FBS. The cells were incubated at $37^{\circ} \mathrm{C}$ in a water-saturated atmosphere of $5 \% \mathrm{CO}_{2} / 95 \%$ air. Confluent cultures were purified on the 10th day by shaking 5 hrs at $180 \mathrm{rpm}$ to remove the suspended cells. Cultures in the flasks were replated into multiwell plates. Subconfluent mixed glial cell cultures were used for PAL31 or GFP overexpression experiment (see below). C6 glioma were obtained from ATCC (Manassas, VA, USA Catalog No. 30-2004). The base medium for this cell line is ATCC-formulated F-12 K Medium. C6 cultures were maintained in ATCC-formulated F-12 K Medium supplemented with 2.5\% FBS and $12.5 \%$ horse serum during cell expansion. C6 glioma were adapted to DMEM + 10\% FBS one passage before cDNA transfection experiments and thereafter [28].

\section{Construction of PAL31 vector and transfection of vector to cultures}

Vectors used in these studies were constructed by inserting the human PAL31 cDNA into the pEGFP-C1 vector (BD Biosciences Clontech, San Jose, CA, USA). Briefly, full-length human PAL31cDNA was amplified from Marathon-Ready cDNA (Clontech, CA, USA) by PCR. Primers for PAL31 were PAL31-forward 5'-GAA,TTC, AAT,GGA,CAT,GAA,GAG, GAG-3'and PAL31-reverse 5'-GAA, GGA,GAA,GAT,GAC,TAA,TCT,AGA-3'. Full length PAL31 cDNA was then ligated into the EcoRI and XbaI site of pEGFP-C1 vector yielding the plasmid $E P$, and verified by DNA sequencing. For cell culture transfection, $5 \mu \mathrm{g}$ each of the recombinant plasmid EP (pPAL31) or EV (pEGFP-C1) were first mixed with TProfect transfection reagent (JF Ji-Feng Biotechnology, Taiwan) in cultured medium containing 5\% FBS. The 
resulted mixtures were added to cultures and incubated for $16 \mathrm{hr}$. The cells were then replaced with growth medium. The resulted transfected cells were used in the present study.

\section{Construction of the pal31 siRNA}

We designed oligonucleotides as pal31 gene hairpin siRNA to knockdown endogenous PAL31 expression in cultures. Two sequences of siRNA were custom-ordered synthesis from Ambion Life Technologies as shown in Additional file 1 supporting information. siRNA was transfected to C6 cultures using a Lipofectamine RNAiMax reagent (Invitrogen) by a protocol suggested by the provider (166 pmol siRNA for cells in $6 \mathrm{~cm}$ dish). Two $\sim$ three days after confirming the knockdown of PAL31 in C6 cells, the cultures were exposed to $\mathrm{H}_{2} \mathrm{O}_{2}$ challenge.

\section{$\mathrm{H}_{2} \mathrm{O}_{2}$ or LPS/IFNy exposure}

GFP or PAL31-overexpressing cells were maintained in $10 \%$ FCS containing medium. Doses of hydrogen peroxide (0.5-1 mM) were added to the culture medium for $4 \mathrm{hr}$. The survived cells were analyzed for the degree of MTT reduction. In the experiments of LPS/IFN $\gamma$ exposure, transduced cells were maintained in serum-containing medium (DMEM +10\% FBS). During LPS /IFN $\gamma$ treatment, the culture medium was switched to DMEM $+4 \%$ FBS. LPS $(4 \mu \mathrm{g} / \mathrm{mL})$ and IFNY $(10 \mathrm{ng} / \mathrm{mL})$ were added to cultures and incubated for 2 hrs $\sim 2$ days. The medium was then saved for nitrite assay, while cells were fixed for immunostaining or harvested for western blot analysis.

\section{Fluorescent immunohistochemistry of spinal cord tissue}

Tissue slides were washed twice with PBS, permeabilized with $0.5 \%$ Triton X-100 in PBS for 5 min, and incubated in $0.05 \%$ Tween 20 in PBS for 5 min at room temperature. Fixed tissue were pre-incubated for $30 \mathrm{~min}$ in PBS containing $2 \% \mathrm{BSA}$ and then incubated for $1 \mathrm{~h}$ at $37^{\circ} \mathrm{C}$ with goat anti-PAL31 (Novus, NB100-1199), ED-1 (Serotec, MCA341) and GFAP (Chemicon, AB5040) (dilution 1:500 1:1000). After three washes with PBS, they were incubated for $30 \mathrm{~min}$ with FITC-conjugated anti-goat antibody (dilution 1:100; Zymed, CA) and Alexa fluro 568 (Molecular probes, A11004). The tissues were incubated in $50 \mathrm{mg} / \mathrm{ml}$ of DAPI in PBS for nuclei staining, and were washed twice with PBS before mounting with artifading reagent. Images of samples were obtained with a fluorescent microscope equipped with fluorescence optics and a CCD camera. Micrography was performed using a 10X and 20X objective and images were processed with imaging software (MetaMorph Imaging System, Universal Imaging Corp, Downingtown, PA, US).

\section{Cell survival MTT assay}

Degree of MTT reduction, which is reduced to a blue formazan product by viable cells, followed a method described in Tsai et al. [26]. Following treatment, aliquots of MTT stock solution $(5 \mathrm{mg} / \mathrm{ml})$ was added to each well and incubated at $37^{\circ} \mathrm{C}$ for $3 \mathrm{hr}$. At the end of incubation, the media were aspirated and cells were solubilized in acid isopropanol (0.04-0.1 N HCl in isopropanol). The resulted solution was measured spectrophotometrically at $590 \mathrm{~nm}$ with background subtraction at $630-690 \mathrm{~nm}$.

\section{The nitrite assay}

The production of nitric oxide (NO) was assayed as the accumulation of nitrite in the medium using colorimetric reaction with Griess reagents ( $1 \%$ sulfanilaminde/ $0.1 \%$ naphthylethylene diamine dihydrochloride/2\% phosphoric acid) as described by Tsai et al. [23] and Tseng et al. [29]. After LPS/IFN $\gamma$ treatment, the culture medium was collected, mixed with Griess reagents and incubated at room temperature for $10 \mathrm{~min}$. The absorbance of the resultant products was measured at $540 \mathrm{~nm}$. Sodium nitrite $\left(\mathrm{NaNO}_{2}\right)$ was used as the standard to calculate nitrogen dioxide $\left(\mathrm{NO}_{2}\right)$ concentrations.

\section{Western blot analysis}

At designated time, cells were homogenized in lysis buffer containing $10 \mathrm{mM}$ Tris, $\mathrm{pH}$ 7.4, $50 \mathrm{mM} \mathrm{NaCl}, 1 \% \mathrm{NP}-40$, $1 \times$ protease inhibitor (Roche, Indianapolis, IN, USA), $30 \mathrm{mM} \mathrm{Na} \mathrm{P}_{2} \mathrm{O}_{7}, 1 \mathrm{mM} \mathrm{Na} \mathrm{VO}_{4}$, and $30 \mathrm{mM} \mathrm{NaF}$. Protein concentration was assayed using a Bio-Rad DC kit (Hercules, CA, USA). The protein extract $(20 \mu \mathrm{g} /$ lane) was next separated on $12.5 \%$ sodium dodecyl sulfate-polyacrylamide gel electrophoresis (SDS-PAGE) and then transferred to a polyvinylidene difluoride filter (Millipore, Bedford, MA, USA) as described [30]. Primary antibodies such as Anp32b (PAL31) (Novus, NB1001199), PCNA (Santa cruz, SC-9857), GFP (Santa cruz, SC-5385), iNOS (Abcam, 47350), pNF-kB (Cell signaling, \#3033), NF-kB (Cell signaling, \#8242) and actin (Santa cruz, SC-1616), were used at 1000-2000 fold dilution. Horseradish peroxidase-conjugated antibody was used as the secondary antibody (Santa Cruz Biotechnology, Santa Cruz, CA, USA). The protein bands were visualized by enhanced chemiluminescence development (PerkinElmer Life Sciences, Waltham, MA, USA). The detailed procedures for the western blotting were the same as described in the New England Nuclear western blot manual, which is provided by the manufacturer.

\section{Statistical analysis}

All measurements were performed blind to each group. Experimental data were expressed as the mean of independent values \pm s.e. and were analyzed using one-way analysis of variance (ANOVA) followed by Bonferroni post hoc test. Data in Figure 1D and Figure 2B was analyzed using two-way ANOVA and Bonferroni post 

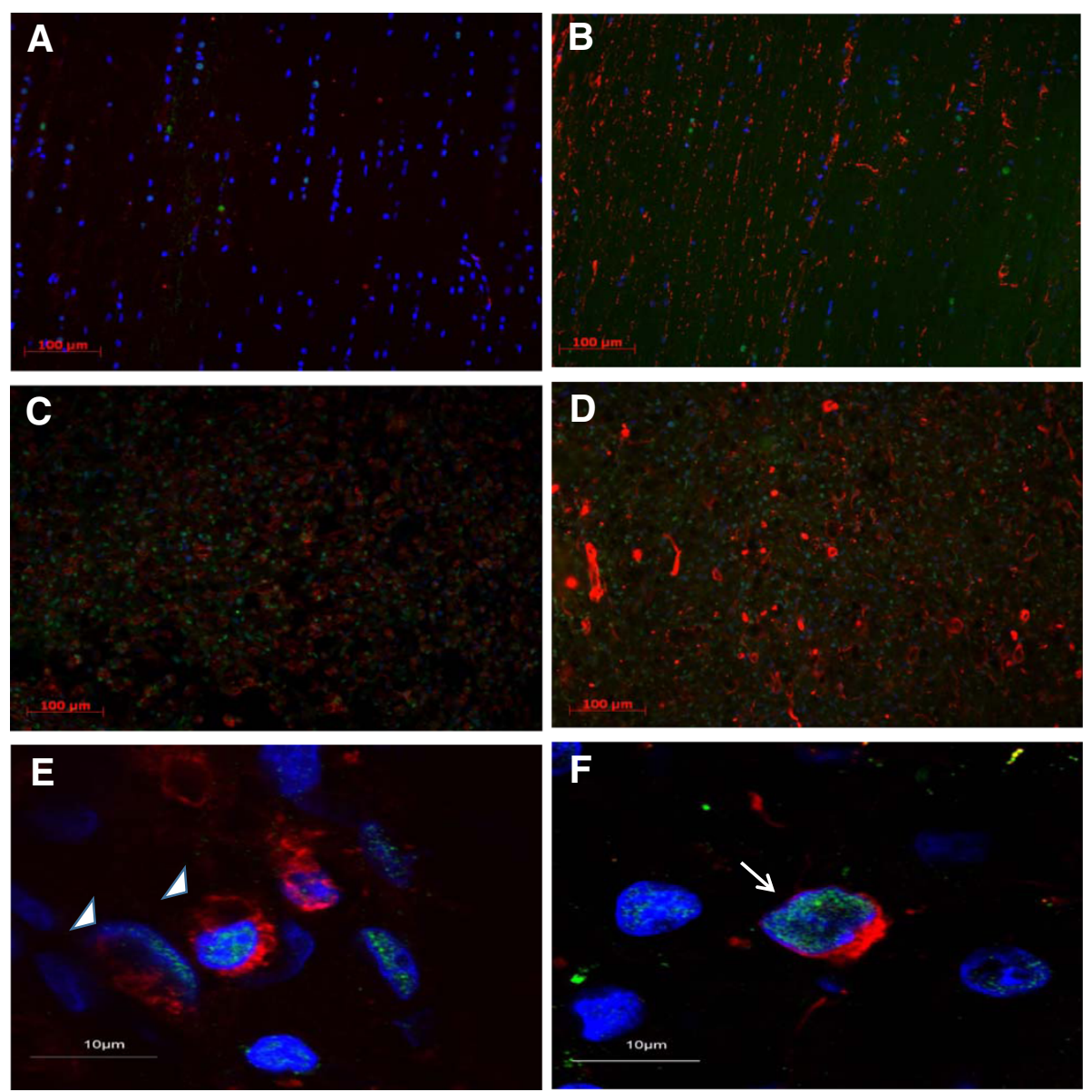

ED-1/PAL31

GFAP/PAL31

Figure 1 Upregulated PAL31 expression was observed not only in microglia/ macrophage but also in glial cells near the injury site. (A) Normal thoracic spinal cord section showing few ED-1 positive cells (red). (B) Normal thoracic spinal cord section showing GFAP positive cells (red). (C) Representative micrograph showing colocalization of upregulated PAL31 (green) with microglia/macrophage (ED1 positive cells) (D) Representative micrograph showing colocalization of upregulated PAL31 with astroglia (GFAP positive cells). (E) High power image showing the colocalization of upregulated PAL31 with ED1 positive macrophage/microglia (arrowhead) (F) High power image demonstrating the colocalization of upregulated PAL31 with GFAP positive astroglia (arrow). Magnification: 200X (A-D) and 1000X (E\&F).

hoc test. P values less than 0.05 were considered statistically significant.

\section{Results}

Upregulated PAL31 expression was observed not only in microglia/macrophage but also in glia cells near the injury site

In our previous study, PAL31 was found to express in the infiltrated macrophages in the epicenter of the injured spinal cord [15]. The amount of PAL31 reached its peak level over 6 days after transection of spinal cord. The present work employed same injury model, collected thoracic spinal cords at one week post-injury and examined whether PAL31 expression was present in other cell types of this injured spinal cord.

As expected, PAL31 upregulation was observed in ED-1-immunoreactive microglia/macrophage (Figure 1C and E; Arrowheads), compared to that in normal cord (Figure 1A). Interestingly, near the transected stump, GFAP-positive astroglia were found to express PAL31 (Figure 1D and F). As shown in Figure 1F (Arrow), PAL31 immunoreactivity (green) co-localized with GFAPpositive cells (red). This phenomenon indicated that PAL31 might have important roles in glia cell after spinal cord injury.

\section{Anti-inflammatory effect of overexpressing PAL31 in primary mixed glia culture}

To evaluate the effects of upregulated PAL31 in glial cells, we constructed full-length PAL31 cDNA and conducted PAL31 overexpressing experiments in primary cultures derived from spinal cord tissues to mimic the interaction of glia and neurons in vivo. To identify cell types in mixed glial cultures prepared from adult spinal cords, we used 

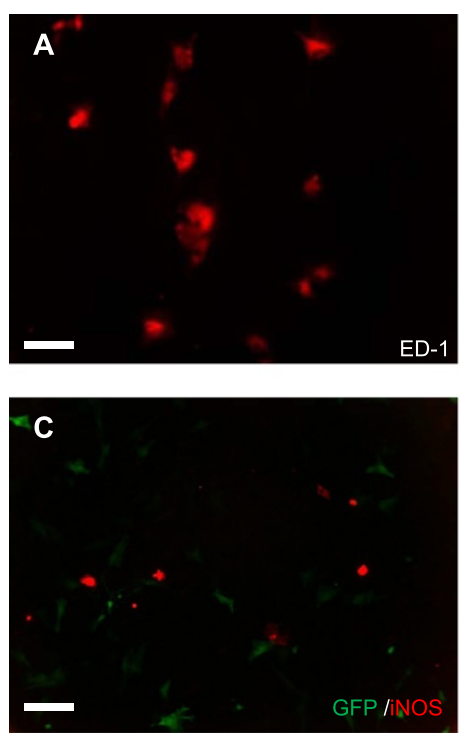

E

70

60

- Glia/GFP+Neurons

- Glia/PAL31+Neurons

50

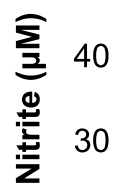

20

10
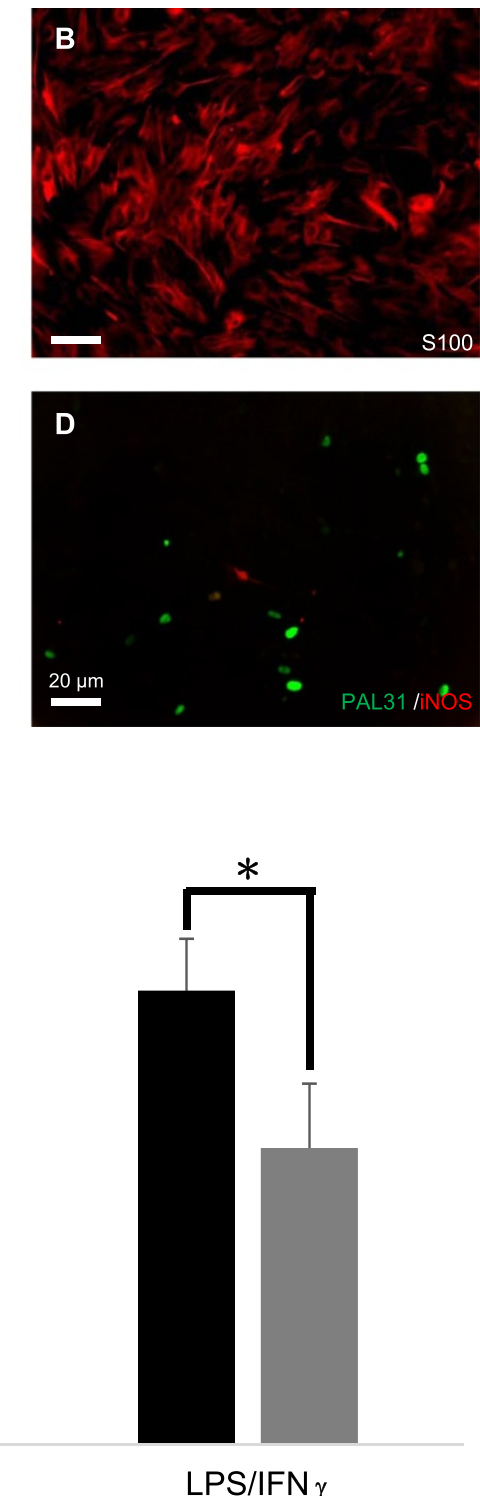

LPS/IFN $\gamma$

control

Figure 2 Overexpression of PAL31 in mixed glial culture effectively reduced LPS/IFNץ stimulation after co-culture with spinal cord neuron-glial cultures. (A) ED-1- immunoreactive microglia/macrophage in confluent mixed glial cultures (B) S100-immunoreactive astroglia in confluent mixed glial cultures (C) LPS/IFNy-stimulated neuron-glial co-cultures (Glia/GFP + neuron) showing expression of both iNOS and GFP (D) LPS/IFNy-stimulated neuron-glial co-cultures (Glia/PAL31+ neuron) showing expression of both iNOS and PAL31. (E) Quantitative analysis of released nitric oxide, as a form of nitrite, in LPS/IFNy-stimulated or non-stimulated neuron-glial co-culture. Mixed glial cultures were transfected with pGFP or PPAL31 before seeding spinal cord neurons. Co-cultures were then treated with LPS/IFNy for 2 days. Medium were saved for nitrite level determination, while cells were processed for immunostaining with iNOS. ${ }^{*} P<0.05, n=4$. PAL31 overexpressing co-cultures $(+L P S / I F N Y)$ compared to GFP overexpressing co-cultures (+LPS/IFNy). Magnification 200X (A-D).

glial cell markers anti-ED-1 [31,32] and anti-S100 [33] for immunocytochemistry. As shown in Figure 2A and $\mathrm{B}$, mixed glial cultures comprised predominant astroglia (S100-immunoreactive cells) and few activated ED-1immunoreactive microglia. Human full-length PAL31 cDNA was successfully made and further inserted into pEGFP-C1 yielding a plasmid with GFP-tagged PAL31. The resulted plasmid each, pEGFP or pPAL31, was added to mixed glial cultures with transfection reagent (T-Profect). As a result, more than $50 \%$ of cells expressed GFP. GFP expression was found in the cytosol of Glia/ GFP-cultures (Figure 2C, green) and in the nucleus of PAL31/GFP-cultures (Figure 2D, green), indicating correct subcellular localization of GFP-tagged PAL31. Spinal cord neuronal cultures were then seeded to GFP- or PAL31-transfected mixed glial cultures (Glia/GFP or 
Glia/PAL31) for co-cultures and examined whether PAL31 overexpression conferred protection against stimulation by LPS and interferon- $\gamma$ (IFN $\gamma$ ). LPS, an endotoxin, is a powerful immune challenge associated with an increase of numerous cytokines and inducible nitric oxide synthase (iNOS) expression. Figure $2 \mathrm{C}$ and $\mathrm{D}$ shows that numbers of LPS/IFN $\gamma$-stimulated iNOS positive cells were less in Glia/PAL31-cocultures than in Glia/GFP-cocultures. The co-cultured media were subjected to nitrite assay to evaluate nitric oxide production. Figure $2 \mathrm{E}$ showed the released nitrite was $53.49 \pm 6.15 \mu \mathrm{M}$ in Glia/GFP + Neurons cocultures stimulated by LPS/IFN $\gamma$. The Glia/ PAL31 + Neurons + LPS/IFN $\gamma$ released significantly less nitrite $(34.94 \pm 7.61 \mu \mathrm{M} ; \mathrm{p}<0.05)$. Thus, overexpressed PAL31 in glia not only attenuated LPS/IFN $\gamma$-stimulated iNOS expression but also reduced the accompanied NO production. To further examine the functions of PAL31 in glial cells, we used homogenous C6 astroglioma cell line to substitute the primary mixed glia.

\section{Overexpressing PAL31 in C6 cell did not affect the cell proliferation}

C6 cells were transfected with pEGFP or pGFP-PAL31 using T-profect. The transfection efficiency reached $>50 \%$ (GFP/phase-contrast superimposed micrograph; Figure 3A and B). GFP-tagged PAL31 was found to express in the nucleus of C6 (Figure 3B), whereas GFP expression was predominant in the cytosol of GFP-C6 (Figure 3A). Western blot analysis of these cultures further confirmed the corrected size of overexpressed PAL31 in C6/PAL31 ( 58 kDa for GFP-tagged PAL31; Figure 3C). The antibody ANP32b could detect endogenous PAL31 protein $(\sim 31 \mathrm{kDa})$ and the GFP antibody detected the tag of the transfected PAL31 and GFP protein. The results of western blot showed that the overexpressed PAL31 cell lysate could be detected by PAL31 and GFP antibodies at $\sim 58 \mathrm{kDa}$ and by anti-GFP at $\sim 27 \mathrm{kDa}$. This indicated correct size of GFP tagged PAL31 with some breakdown signal $(\sim 27 \mathrm{kDa})$. This did not affect the results of our experiment. Endogenous PAL31 was detected by ANP32b at $31 \mathrm{kDa}$ with equivalent level in both C6/ GFP and C6/PAL31 cells (Figure 3C). Levels of actin were used as a loading control. PAL31 had been reported to co-localize with PCNA which participated in DNA replication and repair [16]. Therefore, we examined whether PAL31 overexpressing in C6 affected PCNA expression and the cell's proliferative activity (by MTT assay). As a result, enhanced PAL31 expression in cells did not affect the expression level of PCNA (Figure 3C) as well as the MTT assay results (Figure 3D). The proliferative activity (degree of MTT reduction) in C6 at all time intervals $(0 \sim 72 \mathrm{hr})$ were not significantly different between C6/GFP and C6/PAL31 groups (Figure 3D).

\section{Enhanced PAL31 expression in C6 protected cells from $\mathrm{H}_{2} \mathrm{O}_{2}$ toxicity}

To evaluate the cytoprotective effect of PAL31, $\mathrm{H}_{2} \mathrm{O}_{2}$ $(0.5 \sim 1 \mathrm{mM})$ was added to GFP- or PAL31-transfected C6 for four hours. The survived cells were then analyzed by MTT assay. After $\mathrm{H}_{2} \mathrm{O}_{2}$ treatment, some cells were damaged and detached from the culture plates, only survived cells were able to reduce MTT into a blue formazan product. Figure $4 \mathrm{~A}$ and $\mathrm{B}$ showed that $\mathrm{H}_{2} \mathrm{O}_{2}$ induced dose-dependent cell death in C6/GFP. Compared to $\mathrm{H}_{2} \mathrm{O}_{2}$-treated $\mathrm{C6} / \mathrm{GFP}, \mathrm{C6} / \mathrm{PAL} 31$ were significantly more resistant to $\mathrm{H}_{2} \mathrm{O}_{2}$-toxicity $(\mathrm{P}<0.05$ at $0.5 \mathrm{mM}$ or $1 \mathrm{mM} \mathrm{H}_{2} \mathrm{O}_{2}$; Figure 4B). The survival ratio of C6/GFP by $0.5 \mathrm{mM} \mathrm{H}_{2} \mathrm{O}_{2}$ treatment was $78.52 \pm 7.45 \%$ and that by $1 \mathrm{mM} \mathrm{H}_{2} \mathrm{O}_{2}$ treatment was $41.18 \pm 6.13 \%$. In C6/PAL31 group, the survival ratio by $0.5 \mathrm{mM} \mathrm{H}_{2} \mathrm{O}_{2}$ treatment was $101.32 \pm 8.4 \%$ and that by $1 \mathrm{mM} \mathrm{H}_{2} \mathrm{O}_{2}$ treatment was $64.95 \pm 10.45 \%$.

To further confirm the function of PAL31, we employed pal31 siRNA to C6 culture. As shown in Figure 4C, the expression level of PAL31 protein was substantially reduced by pal31 siRNA at dose $\geqq 166$ picomole $/ 6 \mathrm{~cm}$ dish, compared with the negative control siRNA. To examine the knockdown cells' response to toxin challenge, we subsequently treated cells with $1 \mathrm{mM} \mathrm{H}_{2} \mathrm{O}_{2}$ for 4 hours. Results demonstrated that pal31 siRNA treatment aggravated $\mathrm{H}_{2} \mathrm{O}_{2}$ toxicity to cells. These results consistently suggested that PAL31 might exert a cytoprotective effect on glial cells.

\section{Overexpression of PAL31 in C6 attenuated LPS/IFNY-stimulated NO production}

The transfected C6 (C6/GFP or C6/PAL31) were stimulated by LPS and IFN $\gamma$, the culture medium were collected at 2 days later to evaluate NO production. As shown in Figure 5A, overexpressing PAL31 in C6 cells after LPS/ IFN $\gamma$ treatment produced $31.93 \pm 0.08 \mu \mathrm{M}$ nitrite which was significantly less nitrite level than C6/GFP-LPS/IFN $\gamma$ treated group $(37.13 \pm 0.34 \mu \mathrm{M}$ nitrite; $\mathrm{P}<0.05)$. To investigate whether PAL31 overexpression suppressed NF-kB signaling on LPS/IFN $\gamma$ stimulation, we treated C6/GFP and C6/PAL31 with LPS/IFN $\gamma$ for shorter period (2 hr) and harvested cells for western blot analysis. As a result, Figure $5 \mathrm{C}$ shows a reduced level of phosphorylated NF-kB in LPS/IFN $\gamma$-treated C6/PAL31, compared to that in C6/GFP.

To confirm the overexpressed PAL31 in C6 glial cells may protect neurons from cell death by $\mathrm{NO}$, we used the co-cultures assay (spinal cord neurons seeded to C6/ GFP or C6/PAL31) and collected the conditioned medium to evaluate NO production. And cells were harvested for western blot or morphological analysis. Figure 5B showed that $\mathrm{C} 6 / \mathrm{GFP}+$ Neurons (+LPS/IFN $\gamma$ ) group released 

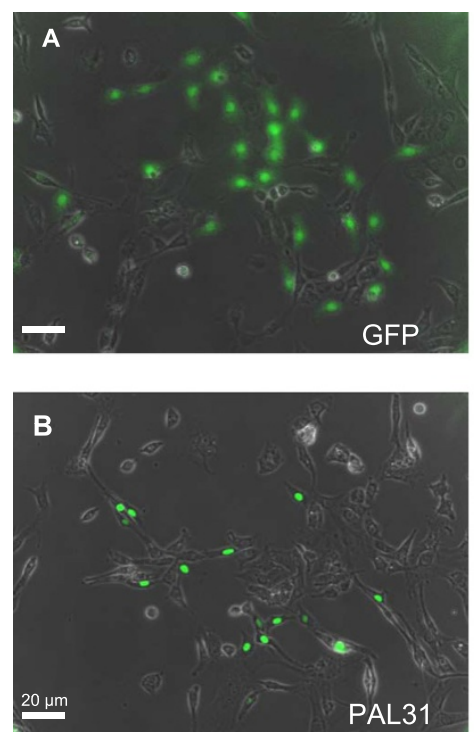

PAL31

GFP

Actin

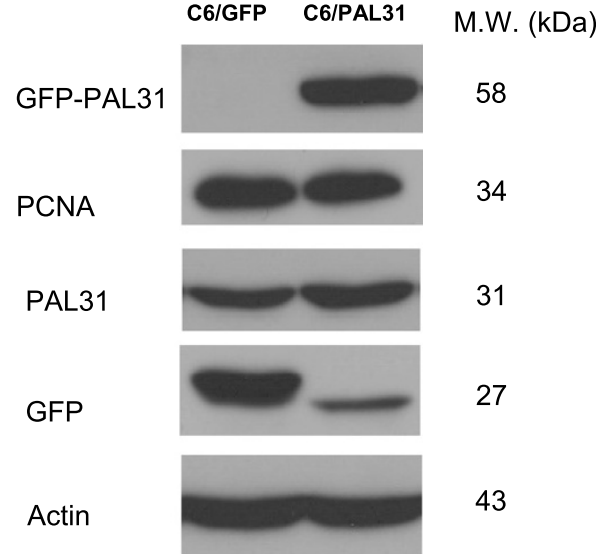

D

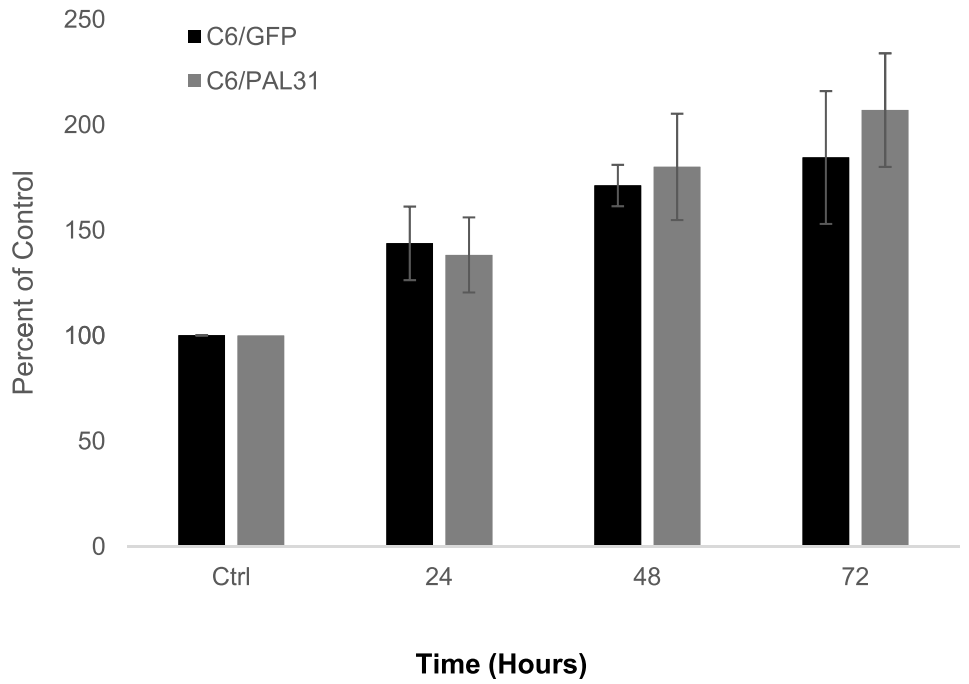

Figure 3 Overexpression of PAL31 in C6 did not affect the cell proliferative activity. (A) GFP/bright field-superimposed micrograph in GFP overexpressing cells showing $>50 \%$ transfective efficiency (B) GFP-PAL31/bright field-micrograph in PAL31 overexpressing C6 showing correct nuclear localization of GFP-tagged PAL31 and transfection effeciency. (C) Western blot analysis showing the expression of GFP ( 27 kDa), GFP-tagged PAL31 ( 58 kDa), PCNA ( 34 kDa), endogenous PAL31 ( 31 kDa) and Actin ( 43 kDa) in GFP- or PAL31-C6 cultures. The level of PCNA, a protein expressing in nuclear during DNA synthesis, in cells did not alter after overexpression of GFP or GFP-tagged PAL31. Actin works as a loading control. (D) MTT assay in the transfected cells at 4 different time intervals (from Ctrl to 72 hours). Ctrl represents the cells after subculture and overnight incubation. The data in each time points were analyzed by two-way ANOVA and Bonferroni post hoc test. No significance, compared GFP and GFP tagged PAL31 groups. $n=3$. Magnification 100X (A-B).

$14.89 \pm 4.5 \mu \mathrm{M}$ nitrite to the conditioned medium. C6/ PAL31 + Neurons group (+LPS/IFN $\gamma)$ generated significantly less nitrite $(6.63 \pm 3.45 \mu \mathrm{M} ; \mathrm{P}<0.05)$ to the medium. Figure 5D demonstrates a reduced iNOS expression in PAL31-overexpressed cocultures than in GFP-cocultures after LPS/IFN $\gamma$ treatment. The numbers of pNF-kB-positive cells in LPS/IFN $\gamma$-treated PAL31 cocultures (Figure 5F) was significantly less than that in LPS/IFN $\gamma$-treated GFP cocultures (Figure 5E). Figure 5G confirms that this response is related to NF-kB-mediated signaling. Combining these data in Figures 2, 3, 4 and 5, our in vitro model could mimic the in vivo model to prove that PAL31 in glia may have the important functions of immunomodulation after spinal cord injury. 
A $\mathrm{H}_{2} \mathrm{O}_{2}(\mathrm{mM}) \quad \mathrm{O}$ 0
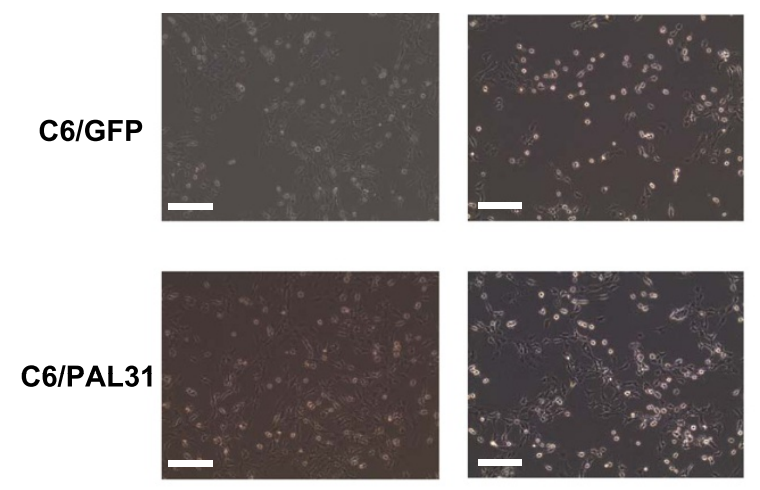

B

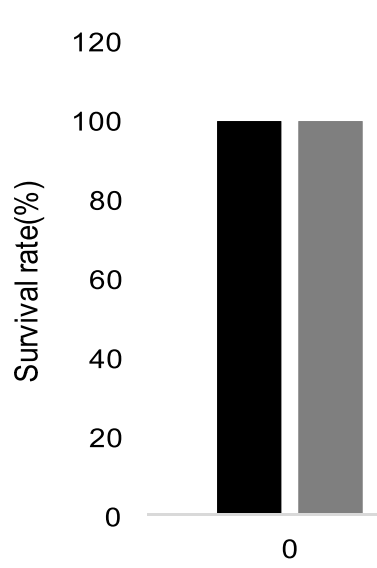

C

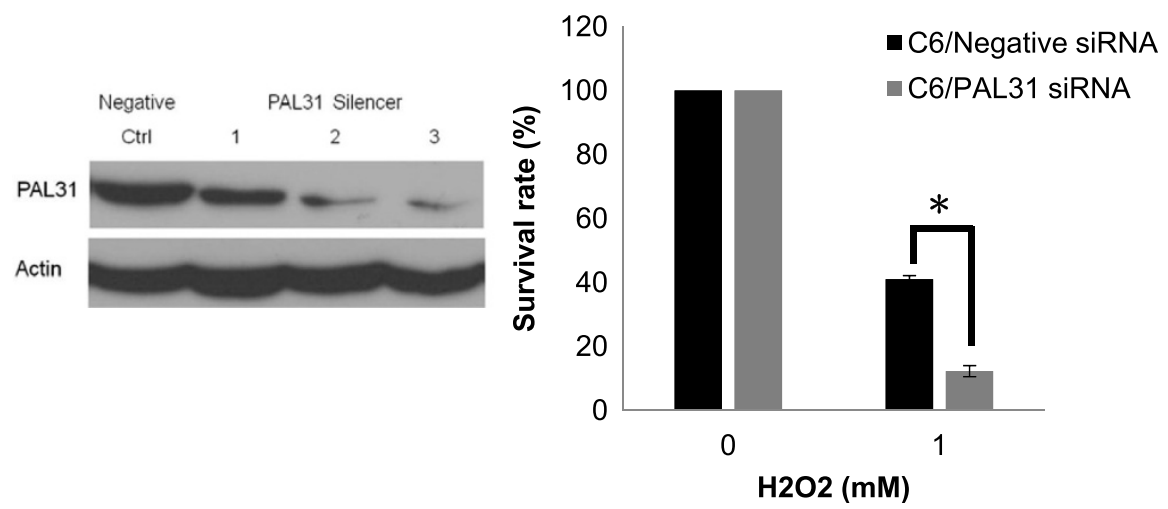

Figure 4 Effect of overexpression or knockdown of PAL31 in $\mathbf{C 6}$ on $\mathrm{H}_{2} \mathrm{O}_{2}$-induced toxicity. (A) Representative micrographs showing $\mathrm{C} 6$ overexpressing GFP or GFP-tagged PAL31 after being treated with $\mathrm{H}_{2} \mathrm{O}_{2}(0 \sim 1 \mathrm{mM})$ for 4 hours. (B) MTT assay in GFP- or GFP-PAL31-overexpressed $\mathrm{C} 6$ after $\mathrm{H}_{2} \mathrm{O}_{2}$ treatment showing significant difference (cytoprotective effect of PAL31) at $0.5 \mathrm{mM}$ and $1 \mathrm{mM} \mathrm{H}_{2} \mathrm{O}_{2}$ treatment between C6/GFP and C6/PAL31 groups. The data in each dosage were analyzed by two-way ANOVA and Bonferroni post hoc test. ${ }_{2} \mathrm{P}<0.05, \mathrm{GFP}\left(+\mathrm{H}_{2} \mathrm{O}_{2}\right) \mathrm{Compared}$ to PAL31 $\left(+\mathrm{H}_{2} \mathrm{O}_{2}\right), \mathrm{n}=4$, at $0.5 \mathrm{mM}$ and $1 \mathrm{mM}$. (C) Western blot analysis of pal31 siRNA-treated C6 showing knockdown of PAL31 expression by PAL31 silencer using 41.5 (lane 1), 83 (lane2), and 166 (lane 3) picomole of pal31 siRNA or 332 picomole negative control. Actin works as a loading control. (D) MTT assay in Negative- or PAL31 silencer transfected $\mathrm{C} 6$ after $\mathrm{H}_{2} \mathrm{O}_{2}$ treatment showing significant difference at 1 mM $\mathrm{H}_{2} \mathrm{O}_{2}$ treatment between C6/Negative and C6/PAL31 siRNA groups. *P $<0.05$, Negative $\left(+\mathrm{H}_{2} \mathrm{O}_{2}\right)$ compared to PAL31 siRNA $\left(+\mathrm{H}_{2} \mathrm{O}_{2}\right), \mathrm{n}=4$. Magnification 100X (A). 


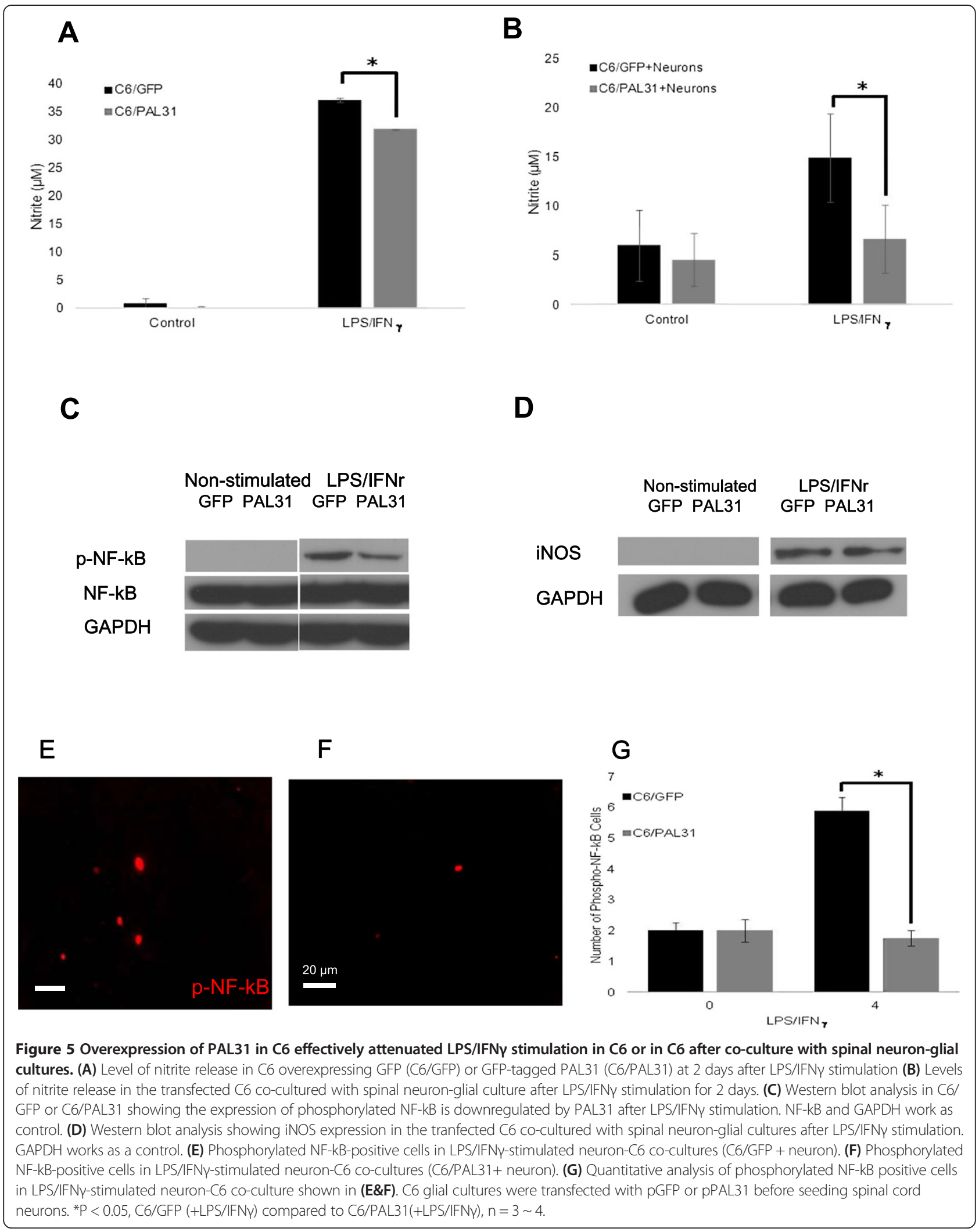




\section{Discussion}

The central observation of the present study is that PAL31 overexpression was found to localize in glia in addition to infiltrated macrophage/microglia in the injured spinal cord. This work examines the role of enhanced PAL31expression in spinal cord cultures, emphasizing on glial cells. Results showed that PAL31 overexpression in mixed glial cultures or in C6 astroglia was beneficial. This conclusion is supported by the following evidence. First, anti-inflammatory effect of overexpressing PAL31 was shown in primary mixed glia culture. Second, enhanced expression of PAL31 in C6 astroglia protected cells from $\mathrm{H}_{2} \mathrm{O}_{2}$ toxicity. By contrast, knockdown expression of PAL31 rendered C6 more susceptible to $\mathrm{H}_{2} \mathrm{O}_{2}$ toxicity. However, this did not affect the proliferative activity. Third, overexpression of PAL31 in C6 astroglia attenuated LPS/IFN $\gamma$-stimulated $\mathrm{NO}$ production. Lastly, inhibiting LPS/IFNy stimulation by PAL31 was observed in glia or C6 after co-culture with neuronal cells. The primary co-culture study demonstrated our in vitro assay mimicking the in vivo model to evaluate the neuron-glial interaction during inflammation.

After LPS/IFN $\gamma$ stimulation, nuclear factor $\kappa \mathrm{B}(\mathrm{NF}-\mathrm{kB})$ is phosphorylated, translocated into nucleus and activate transcription of downstream genes including iNOS [34,35]. In the present study, levels of NF-kB phosphorylation and nitrite were concurrently reduced by PAL31 overexpression in $\mathrm{C} 6$ and co-cultures after LPS/IFN $\gamma$ stimulation. This might suggest that PAL31 suppress NF-kB signaling and thus reduce iNOS expression on LPS/IFN $\gamma$ treatment.

The functions of glia after spinal cord injury include scar formation to prevent further neural damages [36] and protect neurons [37]. To further examine the functions of PAL31 in glial cells, we employed homogenous cell population-C6 astroglia which was generated from rat glioma and expressed S100 protein [38]. Furthermore, the transfection efficiency of GFP-tagged PAL31 in C6 was higher than in primary mixed glial culture. As shown in Figure 3B, the overexpressed PAL31 was specifically localized in the nucleus due to its nuclear localization signal in its protein sequence, consistent with previous studies $[39,40]$. Western blot analysis of these transfected C6 further confirms overexpression of GFP-tagged PAL31 with correct protein size and immunoreactivity (Figure 3C). PAL31 had been reported to co-localize with PCNA which participated in DNA replication and repair [16]. The cell cycle progression in S phase needs PAL31 [40]. However, the present results could not obtain similar effect. Overexpression of PLA31 did not alter PCNA level neither the proliferative activity in C6 cells (Figure 3C and D). Interestingly, PAL31 overexpressing in C6 could significantly reduce $\mathrm{H}_{2} \mathrm{O}_{2}$-induced cell death (Figure 4). This effect might be due to overexpressed PAL31 working as a caspase-3 substrate [17], rendering the
PAL31-transfected cells more resistant to $\mathrm{H}_{2} \mathrm{O}_{2}$ toxicity. By contrast, PAL31 knockdown cells were more susceptible to $\mathrm{H}_{2} \mathrm{O}_{2}$ challenge. The results of over-expression and the small interfering RNA (siRNA) knockdown of PAL31 in C6 cells further suggested that the function of PAL31 might be negatively regulated.

Astrocytes become "reactive" in response to spinal cord injury. Nevertheless, the harmful and beneficial functions of reactive astrocytes are not well understood. The roles of astroglia in neural regeneration after spinal cord injury were still unclear. Immunomodulation of astroglia might play an important role. Previous studies demonstrated that iNOS upregulation in glia cells caused neurodegeneration in Parkinson's disease [41] and the activated immune cell in brain were correlated with Alzheimer disease [42]. These studies gave us a hit to overcome the unfavorable microenvironment for regeneration after spinal cord injury. Modulation of astroglial reactivity should be paid more attention. In our previous studies of spinal cord regeneration, PAL31 was suggested to play a key role in spinal cord regeneration after injury [2]. The present findings are in keeping with our previous observations that both microglia and GFAP positive astroglia enhanced PAL31 expression near the lesion site after transected spinal cord injury (Figure 1). This phenomenon might be related to the important endogenous regenerative mechanisms. Reactive astrocytes exert both pro- and anti-inflammatory functions at different locations and at different times in response to injury and during repair. There were many studies focused on astroglia as a therapeutic target [43]. PAL31 effectively reduced LPS/IFN $\gamma$ stimulation and also protected cells from $\mathrm{H}_{2} \mathrm{O}_{2}$ toxicity in astroglia in the present study. PAL31 may provide new means to study the activities and regulation of reactive astrocytes after CNS insults in vivo.

\section{Conclusions}

In conclusion, the present study provides evidence that overexpressed PAL31 in glia cells could reduce LPS/ IFN $\gamma$ stimulation and $\mathrm{H}_{2} \mathrm{O}_{2}$ toxicity. Together with our previous study of immunomodulatory role of PAL31 in macrophages after SCI, this study suggests a beneficial role of PAL31 in glial cells after injury. A better understanding of glial cell roles during the complex multicellular interactions after CNS insults is important in developing potential therapeutic interventions.

\section{Additional file}

Additional file 1: PAL31 knockdown clones showing the sequence of SiRNA of PAL31.

Competing interests

The authors declare that they have no competing interests. 


\section{Authors' contributions}

FWT and DYL carried out cell culture and IHC studies. FWT and MJT participated in the design of the study and drafted the manuscript. MJT, WCH and $\mathrm{HC}$ conceived of the study, participated in its design and coordination, and collectively prepared the manuscript. All authors read and approved the final manuscript.

\section{Acknowledgments}

This work was supported financially by research grants (V102E6-001, V101E6001, V100S6-001, and V9956-001) from the Taipei Veterans General Hospital in Taiwan, by grants (NSC 98-2314-B-075-007-MY2, NSC 99-2628-B-010-009-MY3, NSC 101-2314-B-010-006-MY3, NSC102-2314-B-075-052) from the National Science Council in Taiwan, and by a grant from the Ministry of Education (Aim for the Top University Plan).The authors thank Ms. Ching-Jung Chen and Mr. Boruei Chen for their excellent assistance. We thank Ms. Hsin-Yi Huang from the Biostatistics Task Force of Taipei Veterans General Hospital for her statistical assistance.

\section{Author details}

'Department and Institute of Pharmacology, School of Medicine, National Yang-Ming University, Taipei, Taiwan. ${ }^{2}$ Neural Regeneration Laboratory, Neurological Institute, Taipei Veterans General Hospital, No 322, Shih-Pai Road, Sec. 2, Taipei 112, Taiwan. ${ }^{3}$ Center for Neural Regeneration, Neurological Institute, Taipei Veterans General Hospital, Taipei, Taiwan. ${ }^{4}$ Faculty of Medicine, School of Medicine, National Yang-Ming University, Taipei, Taiwan

Received: 13 March 2014 Accepted: 1 June 2014 Published: 17 July 2014

\section{References}

1. Tator $\mathrm{CH}$ : Experimental and clinical studies of the pathophysiology and management of acute spinal cord injury. J Spinal Cord Med 1996, 19(4):206-214

2. Dumont RJ, Okonkwo DO, Verma S, Hurlbert RJ, Boulos PT, Ellegala DB, Dumont AS: Acute spinal cord injury, part I: pathophysiologic mechanisms. Clin Neuropharmacol 2001, 24(5):254-264.

3. Dusart I, Schwab ME: Secondary cell death and the inflammatory reaction after dorsal hemisection of the rat spinal cord. Eur J Neurosci 1994 6(5):712-724.

4. Popovich PG, Guan Z, McGaughy V, Fisher L, Hickey WF, Basso DM: The neuropathological and behavioral consequences of intraspinal microglial/ macrophage activation. J Neuropathol Exp Neurol 2002, 61(7):623-633.

5. Keane RW, Davis AR, Dietrich WD: Inflammatory and apoptotic signaling after spinal cord injury. J Neurotrauma 2006, 23(3-4):335-344.

6. Gonzalez CL, Kolb B: A comparison of different models of stroke on behaviour and brain morphology. Eur J Neurosci 2003, 18(7):1950-1962.

7. Beattie MS: Inflammation and apoptosis: linked therapeutic targets in spinal cord injury. Trends Mol Med 2004, 10(12):580-583.

8. Pekny M, Nilsson M: Astrocyte activation and reactive gliosis. Glia 2005, 50(4):427-434

9. Sofroniew MV: Molecular dissection of reactive astrogliosis and glial scar formation. Trends Neurosci 2009, 32(12):638-647.

10. Hall ED, Springer JE: Neuroprotection and acute spinal cord injury: a reappraisal. NeuroRx 2004, 1(1):80-100.

11. Hall ED, Braughler JM: Central nervous system trauma and stroke. II. Physiological and pharmacological evidence for involvement of oxygen radicals and lipid peroxidation. Free Radic Biol Med 1989, 6(3):303-313.

12. Merrill JE, Murphy SP, Mitrovic B, Mackenzie-Graham A, Dopp JC, Ding M, Griscavage J, Ignarro $L$, Lowenstein $C J$ : Inducible nitric oxide synthase and nitric oxide production by oligodendrocytes. J Neurosci Res 1997, 48(4):372-384.

13. Grzybicki D, Gebhart GF, Murphy S: Expression of nitric oxide synthase type II in the spinal cord under conditions producing thermal hyperalgesia. J Chem Neuroanat 1996, 10(3-4):221-229.

14. Cai D, Qiu J, Cao Z, McAtee M, Bregman BS, Filbin MT: Neuronal cyclic AMP controls the developmental loss in ability of axons to regenerate. J Neurosci 2001, 21(13):4731-4739.

15. Shen LF, Cheng H, Tsai MC, Kuo HS, Chak KF: PAL31 may play an important role as inflammatory modulator in the repair process of the spinal cord injury rat. J Neurochem 2009, 108(5):1187-1197.
16. Oda M, Sun W, Hattori N, Tanaka S, Shiota K: PAL31 expression in rat trophoblast giant cells. Biochem Biophys Res Commun 2001, 287(3):721-726.

17. Sun W, Kimura H, Hattori N, Tanaka S, Matsuyama S, Shiota K: Proliferation related acidic leucine-rich protein PAL31 functions as a caspase-3 inhibitor. Biochem Biophys Res Commun 2006, 342(3):817-823.

18. Zai $L J$, Wrathall JR: Cell proliferation and replacement following contusive spinal cord injury. Glia 2005, 50(3):247-257.

19. Cheng H, Cao Y, Olson L: Spinal cord repair in adult paraplegic rats: partial restoration of hind limb function. Science 1996, 273(5274):510-513.

20. Lee MJ, Chen CJ, Huang WC, Huang MC, Chang WC, Kuo HS, Tsai MJ, Lin $Y L$, Cheng $H$ : Regulation of chondroitin sulphate proteoglycan and reactive gliosis after spinal cord transection: effects of peripheral nerve graft and fibroblast growth factor 1. Neuropathol Appl Neurobiol 2011, 37(6):585-599.

21. Huang WC, Kuo WC, Cherng JH, Hsu SH, Chen PR, Huang SH, Huang MC, Liu JC, Cheng $\mathrm{H}$ : Chondroitinase $A B C$ promotes axonal re-growth and behavior recovery in spinal cord injury. Biochem Biophys Res Commun 2006, 349(3):963-968.

22. Huang WC, Kuo WC, Hsu SH, Cheng CH, Liu JC, Cheng H: Gait analysis of spinal cord injured rats after delivery of chondroitinase $A B C$ and adult olfactory mucosa progenitor cell transplantation. Neurosci Lett 2010, 472(2):79-84.

23. Tsai MJ, Weng CF, Shyue SK, Liou DY, Chen $\mathrm{CH}$, Chiu CW, Yang TH, Pan HA, Liao Rl, Kuo HS, Huang MC, Huang WC, Hoffer BJ, Cheng H: Dual effect of adenovirus-mediated transfer of BMP7 in mixed neuron-glial cultures: neuroprotection and cellular differentiation. J Neurosci Res 2007 85(13):2950-2959.

24. Tsai MJ, Chen YM, Weng CF, Liou DY, Yang HC, Chen CH, Liao Rl, Kuo FS, Chiu CW, Kuo HS, Huang MC, Lin YL, Lee MJ, Kuo WC, Huang WC, Cheng H: Enhanced expression of glycine $\mathrm{N}$-methyltransferase by adenovirusmediated gene transfer in CNS culture is neuroprotective. Ann N Y Acad Sci 2010, 1199:194-203.

25. Tsai MJ, Tsai SK, Hu BR, Liou DY, Huang SL, Huang MC, Huang WC, Cheng H, Huang SS: Recovery of neurological function of ischemic stroke by application of conditioned medium of bone marrow mesenchymal stem cells derived from normal and cerebral ischemia rats. J Biomed Sci 2014 21:5.

26. Tsai MJ, Lee EH: Nitric oxide donors protect cultured rat astrocytes from 1-methyl-4-phenylpyridinium-induced toxicity. Free Radic Biol Med 1998, 24(5):705-713.

27. Tsai MJ, Lee EH: Differences in the disposition and toxicity of 1-methyl-4phenylpyridinium in cultured rat and mouse astrocytes. Glia 1994, 12(4):329-335.

28. Lin YL, Tsai MJ, Lo MJ, Chang SE, Shih YH, Lee MJ, Kuo HS, Kuo WC, Huang WC, Cheng $H$, Huang MC: Evaluation of the antiangiogenic effect of Kringle 1-5 in a rat glioma model. Neurosurgery 2012, 70(2):479-489. discussion 489-90.

29. Tseng FW, Tsai MJ, Yu LY, Fu YS, Huang WC, Cheng H: Comparative effects of bone marrow mesenchymal stem cells on lipopolysaccharide-induced microglial activation. Oxid Med Cell Longev 2013, 2013:234179.

30. Tsai MJ, Weng CF, Yu NC, Liou DY, Kuo FS, Huang MC, Huang WC, Tam K, Shyue SK, Cheng $\mathrm{H}$ : Enhanced prostacyclin synthesis by adenoviral gene transfer reduced glial activation and ameliorated dopaminergic dysfunction in hemiparkinsonian rats. Oxid Med Cell Longev 2013 2013:649809.

31. Graeber MB, Streit WJ: Microglia: immune network in the CNS. Brain Pathol 1990, 1(1):2-5.

32. Slepko N, Levi G: Progressive activation of adult microglial cells in vitro. Glia 1996, 16(3):241-246.

33. Donato R, Sorci G, Riuzzi F, Arcuri C, Bianchi R, Brozzi F, Tubaro C, Giambanco I: S100B's double life: intracellular regulator and extracellular signal. Biochim Biophys Acta 2009, 1793(6):1008-1022.

34. Nomura Y: NF-kappaB activation and IkappaB alpha dynamism involved in iNOS and chemokine induction in astroglial cells. Life Sci 2001 68(15):1695-1701.

35. Hwang J, Lee HJ, Lee WH, Suk K: NF-kappaB as a common signaling pathway in ganglioside-induced autophagic cell death and activation of astrocytes. J Neuroimmunol 2010, 226(1-2):66-72.

36. Barnabe-Heider F, Goritz C, Sabelstrom H, Takebayashi H, Pfrieger FW, Meletis K, Frisen J: Origin of new glial cells in intact and injured adult spinal cord. Cell Stem Cell 2010, 7(4):470-482. 
37. Faulkner JR, Herrmann JE, Woo MJ, Tansey KE, Doan NB, Sofroniew MV: Reactive astrocytes protect tissue and preserve function after spinal cord injury. J Neurosci 2004, 24(9):2143-2155.

38. Benda P, Lightbody J, Sato G, Levine L, Sweet W: Differentiated rat glial cell strain in tissue culture. Science 1968, 161(3839):370-371.

39. Mutai H, Toyoshima Y, Sun W, Hattori N, Tanaka S, Shiota K: PAL31, a novel nuclear protein, expressed in the developing brain. Biochem Biophys Res Commun 2000, 274(2):427-433.

40. Sun W, Hattori N, Mutai H, Toyoshima Y, Kimura H, Tanaka S, Shiota K: PAL31, a nuclear protein required for progression to the $S$ phase. Biochem Biophys Res Commun 2001, 280(4):1048-1054.

41. Liberatore GT, Jackson-Lewis V, Vukosavic S, Mandir AS, Vila M, McAuliffe WG, Dawson VL, Dawson TM, Przedborski S: Inducible nitric oxide synthase stimulates dopaminergic neurodegeneration in the MPTP model of Parkinson disease. Nat Med 1999, 5(12):1403-1409.

42. Armato U, Chakravarthy B, Pacchiana R, Whitfield JF: Alzheimer's disease: an update of the roles of receptors, astrocytes and primary cilia (review). Int J Mol Med 2013, 31(1):3-10.

43. Colangelo AM, Alberghina L, Papa M: Astrogliosis as a therapeutic target for neurodegenerative diseases. Neurosci Lett 2014, 565(17):59-64.

doi:10.1186/1423-0127-21-60

Cite this article as: Tseng et al:: Cytoprotective and anti-inflammatory effects of PAL31 overexpression in glial cells. Journal of Biomedical Science 2014 21:60.

\section{Submit your next manuscript to BioMed Central and take full advantage of:}

- Convenient online submission

- Thorough peer review

- No space constraints or color figure charges

- Immediate publication on acceptance

- Inclusion in PubMed, CAS, Scopus and Google Scholar

- Research which is freely available for redistribution 